\title{
PREVALENCE OF METHICILLIN RESISTANT STAPHYLOCOCCUS AUREUS AMONG FOOD HANDLERS IN DUHOK CITY
}

\author{
Masood Abdulkareem Abdulrahman ${ }^{\mathrm{a}, *}$, Arazoo Issa Taher ${ }^{\mathrm{b}}$ \\ ${ }^{\text {a }}$ Community Health Department, Shekhan Technical College of Health, Duhok Polytechnic University - \\ Masood.Abdulkareem@dpu.edu.krd \\ ${ }^{b}$ Bardarash Technical Institute, Duhok Polytechnic University- arezu.issa@gmail.com
}

\begin{abstract}
:
Food handlers harbouring $S$. aureus on their noses or in hands are considered as the main source of food contamination. Antibiotic resistance in $S$. aureus is a serious issue. The study aimed to find out the prevalence of methicillin-resistant $S$. aureus among food handlers in restaurants of Duhok city. Nasal and hand swabs were taken from 200 food handlers. The collected swabs inoculated on mannitol salt agar and incubated at $37^{\circ} \mathrm{C}$ for $24-48 \mathrm{~h}$. Isolates identified as $S$. aureus underwent antimicrobial sensitivity testing to methicillin and vancomycin on Mueller Hinton agar. A total of $74(37 \%)$ out of 200 cultures of food handlers were found to be colonized with $S$. aureus. 53 (26.5\%) isolated from the nose, compared with $8(4.0 \%)$ from hands and $13(6.5 \%)$ from both. $27 \%$ of the food handlers were found to be MRSA carrier, and none of the isolates were resistant to Vancomycin. The study revealed a high prevalence of MRSA among food handlers in Duhok city. Food handlers in public places are required to go through regular screening for both nasal and skin carriage of $S$. aureus for the early detection and treatment of carriers. This is to protect the community from staphylococcal food poisoning and the spread of resistant $S$. aureus strains among the population.
\end{abstract}

KEYWORDS: MRSA, Food handlers; Prevalence; Duhok.

\section{INTRODUCTION}

Staphylococcus aureus is a common commensal of the skin and mucosal membranes of humans, with estimates of 20 $30 \%$ for persistent and $60 \%$ for intermittent asymptomatic carriers. The presence of these bacteria in food occurs frequently due to inappropriate manipulation of food by carriers (Alhashimi et al., 2017). Globally, foodborne diseases are one of the main health problems and the World Health Organization (WHO) estimated that they caused 600 million foodborne illnesses and 420,000 deaths in 2010. The global burden of foodborne diseases was 33 million disability adjusted life years (WHO, 2015). Nasal carriage of $S$. aureus in food handlers is the major risk of staphylococcal food poisoning, but the skin is much less. Food handlers carrying enterotoxin-producing $S$. aureus in their noses or on their hands are concerned as the main source of food contamination, by either manual contact or through respiratory discharges (Ahmed and Mashat, 2014). Moreover, antibiotic resistance in S. aureus is a serious issue and the resistance occurred in different media and on different surfaces. Strains of methicillin-resistant Staphylococcus aureus (MRSA) are of special concern as they responsible for the substantial causes of morbidity and mortality worldwide. Methicillin-resistant $S$. aureus is resistant to all available penicillin and other lactam antimicrobial drugs. Data collected from 28 countries during 2009-2012 showed a significant increase in the percentage of MRSA isolates that reached up to $50 \%$ in some countries like Portugal and Romania (Castro et al., 2015). The incidence of community-acquired $S$. aureus infections has been rising with the increasing emergence of MRSA, earlier MRSA infections were limited to the hospitals, but it has been steadily more reported in the community (Mainous et al., 2006). Although, vancomycin is one of the first line antibiotics that used to treat patients with MRSA but recently cases of vancomycin resistance have been also recorded (Shokouhi et al., 2017). Staphylococcal food poisoning outbreaks (SFPOs) are ranked in the last years as the first cause of food-borne illness outbreaks in many countries. $S$. aureus has attributed to $23 \%$ of the food-borne disease outbreaks in 2014 (Mossong et al., 2015).SFPOs are under-reported for many reasons such as the short incubation period 30 minutes to 6 hours, only $10 \%$ of SFPOs patients visit a health facility, the medical staff usually does not request a stool analysis and even if a stool analysis is carried out, the routine procedures frequently do not involve testing for the existence of enterotoxigenic $S$. aureus unless particularly requested by the medical staff (Mossong et al., 2015).

The main objective of this study is to evaluate the prevalence of nasal and skin carriage of $S$. aureus and MRSA and to examine the vancomycin sensitivity pattern amongst food handlers working in different types of restaurants in Duhok city, Kurdistan Region, Iraq.

A cross-sectional study was adopted to achieve our objectives. The study was conducted from $1^{\text {st }}$ November 2017 to $31^{\text {st }}$ July 2018.

\section{METHODS}

\subsection{Sampling}

At the time of the study, there were (314) different restaurants in Duhok city. The restaurants classified by Directorate of Preventive Health Affairs in Duhok into three categories casual dining (popular), fast foods and fine dining restaurants. The classification depended on according to certain criteria like type of services and total area (Directorate of Preventive Health Affairs, 2017). The available restaurants are divided into three types (strata), a stratified sampling procedure was used to enrol 40 restaurants from Duhok city through choosing proportionate number of restuarants from each strata (restaurants lists) by simple random sampling procedure (table1). These restaurants are distributed throught all quarters, sectors and main malls in the city. Two hunderd samples were taken from the selected resturants. 
Table 1. Number \& percentage of restaurants stratified by types

\begin{tabular}{|c|c|c|c|}
\hline \multirow{2}{*}{$\begin{array}{c}\text { Types of } \\
\text { Restaurants }\end{array}$} & \multicolumn{2}{|c|}{$\begin{array}{c}\text { Total number of } \\
\text { Restaurants }\end{array}$} & \multirow{2}{*}{$\begin{array}{c}\text { Number of } \\
\text { selected } \\
\text { Restaurants }\end{array}$} \\
\cline { 2 - 3 } & No. & $\%$ & 27 \\
\hline $\begin{array}{c}\text { Casual dining } \\
\text { (Popular) }\end{array}$ & 219 & 69.7 & 6 \\
\hline Fine dining & 41 & 13.1 & 7 \\
\hline Fast food & 54 & 17.2 & 40 \\
\hline Total & 314 & 100.0 & 4 \\
\hline
\end{tabular}

\subsection{Inclusion criteria}

All persons who are serving in the enrolled restaurants and involved in the process of food preparation and introducing it like cooks, waiters and kitchen assistants are included in the study.

\subsection{Exclusion criteria}

Other restaurants' staffs such as administrative staff, owners and others who do not have contact with food preparation or serving are excluded from the study.

\subsection{Isolation and identification of $S$. aureus}

From each food handler two samples were taken one from nasal cavities and the other from their hands, and two different swabs were utilized for each of them. One sterile swab was used for both anterior nares (left and right) of the workers; the swab was inserted $1-2 \mathrm{~cm}$ inside the nasal cavity with rotating 2-3 seconds around the insides of each nostril. To inhibit any discomfort, the used swabs were moistened with sterile distilled water. Moreover, another sterile swab was used to swab both hands of the food handlers, involving the rest of both hands and in between fingers about five seconds for each hand. Then the swabs transferred into transport media then cultured in Mannitol salt agar (Oxoid) and incubated aerobically at $37^{\circ} \mathrm{C}$ for 24 to 48 hours. Then isolates were considered $S$. aureus by using gram staining, standard biochemical reactions (catalase and coagulase tests) and fermentation on mannitol salt agar.

\subsection{Antibiotic susceptibility testing of $S$. aureus}

Antimicrobial susceptibility was performed on MuellerHinton agar (LAB M, UK ) using Kirby-Bauer disk diffusion method according to diameter interpretation standards charts. The bacterial suspension prepared by emulsifying in $5 \mathrm{ml}$ of sterile normal saline until turbidity is approximately equivalent to that of the McFarland No. 0.5 turbidity standard. A sterile swab was dipped into the bacterial mixture; removed excess inoculum by squeezing on the wall of the test tube. Then, using this swab the surface of the agar was then uniformly and lightly inoculated. Then by sterile forceps two antibiotic disks (Methicillin $5 \mu \mathrm{g}$ and

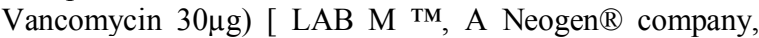
United Kingdom] were placed for each plate. The plates were incubated at $35^{\circ} \mathrm{C}$ for 24 hours. After incubation time finished, inhibition zones that observed on agar plate were measured according to standard chart (Vandepitte et al., 2013; CLSI, 2017).

\subsection{Data analysis}

All data pertaining to demographic information, and laboratory results were entered and edited using Microsoft Word 2010 for windows 10. Data analysis was conducted with the Statistical Package for Social Science (SPSS) software version 23. Descriptive statistics was provided for the demographic data and questionnaire of the study. Chisquare test was utilized to estimate the association of the studied variables with MRSA. P-Values $\leq 0.05$, was considered statistically significant.

\subsection{Ethical considerations}

Before starting the study, it was approved first by the Scientific Committee of Shekhan Technical College of Health in Duhok Polytechnic University. At the same time, this study was approved by the Research Ethical Committee of the Directorate General of Health of Duhok governorate was obtained.

\section{RESULTS}

\subsection{Demographic characteristics}

There were 200 food handlers working in 40 different restaurants, and all participants were males. The main age group of the subjects was 20-29 years. About two thirds of the participants were high school educated and illiterate, $37 \%$ and $35 \%$, respectively, and only $3.5 \%$ of the participants were graduates of institute or university. Meanwhile about $36.5 \%$ of food handlers were involved in food preparation (chefs) followed by waiters and kitchen assistants (including cleaners and dishwashers) $35.5 \%$ and $24 \%$, respectively. These characteristics are presented in table 2 .

Table 2. Demographic characteristics of the food handlers.

\begin{tabular}{|c|c|c|}
\hline \multicolumn{2}{|c|}{ Demographic Variables } & Number (\%) \\
\hline & $<20$ & $29(14.5)$ \\
Age & $20-29$ & $80(40.0)$ \\
(years) & $30-39$ & $38(19.0)$ \\
& 40 and more & $53(26.5)$ \\
\hline \multirow{3}{*}{ Education } & Illiterate & $70(35)$ \\
level & Primary school & $49(24.5)$ \\
& High school & $74(37)$ \\
& Institute or university & $7(3.5)$ \\
\hline \multirow{4}{*}{ Job title } & Cook & $73(36.5)$ \\
& Waiters & $71(35.5)$ \\
& Kitchen assistants & $48(24)$ \\
& Others & $8(4)$ \\
\hline
\end{tabular}

\subsection{Types of restaurants and number of food handlers}

200 workers form 40 restaurants are included in the study. Casual dining (popular) restaurants represent the bulk of included restaurants $27(67.5 \%)$ followed by fast food restaurants 7 $(17.5 \%)$ and fine dining restaurants $6(15 \%)$ respectively. Out of 200 food handlers included in the study, more than half of them $105(52.5 \%)$ belonged to casual dining restaurants and 59 $(29.5 \%)$ of them were from fine dining restaurants while the least number $36(18 \%)$ were from fast food restaurants, as shown in table 3.

Table 3. Classification of restaurants and distribution of food handlers

\begin{tabular}{|c|c|c|}
\hline \multirow{2}{*}{ Types of restaurants } & \multicolumn{2}{|c|}{ Food Handlers } \\
\cline { 2 - 3 } & No. (\%) & No. $(\%)$ \\
\hline Casual dining (popular) & $27(67.5)$ & $105(52.5)$ \\
\hline Fast food & $7(17.5)$ & $36(18.0)$ \\
\hline Fine dining & $6(15)$ & $59(29.5)$ \\
\hline Total & $40(100.0)$ & $200(100.0)$ \\
\hline
\end{tabular}

\subsection{Staphylococcus aureus carriers and age groups}

The prevalence of $S$. aureus carriers among food handlers was $37 \%$ (74 out of 200 food handlers). The distribution of $S$. aureus carriers according to age groups are shown in table 4 . There were no significant association between age group and $s$. aureus carriers. 
Table 4. Staphylococcus aureus carriers and age group

\begin{tabular}{|c|c|c|c|}
\hline \multirow{2}{*}{$\begin{array}{c}\text { Age group in } \\
\text { years }\end{array}$} & \multicolumn{2}{|c|}{ Staphylococcus aureus carriers } & \multirow[b]{2}{*}{ Total (\%) } \\
\hline & Positive (\%) & Negative (\%) & \\
\hline$<20$ & $14(18.9)$ & $15(11.9)$ & $29(14.5)$ \\
\hline $20-29$ & $23(31.1)$ & $57(45.2)$ & $80(40)$ \\
\hline $30-39$ & $15(20.3)$ & $23(18.3)$ & $38(19)$ \\
\hline 40 and above & $22(29.7)$ & $31(24.6)$ & $53(26.5)$ \\
\hline Total & $74(100.0)$ & $126(100.0)$ & $200(100.0)$ \\
\hline
\end{tabular}

\subsection{Prevalence of $\mathrm{S}$. aureus carriers according to the anatomical site}

Table 5 shows that in $71.6 \%$ of carriers, the $S$. aureus was isolated from their noses only and in $10.8 \%$ was isolated from the hands (skin) only, while in $17.6 \%$ the $S$. aureus was isolated from both sites (nasal cavity and hand). There were highly significant differences between the anatomical sites of isolation $(P$ - value $<0.001)$

Table 5. Prevalence of $S$. aureus carriers according to the anatomical site

\begin{tabular}{|c|c|c|}
\hline \multirow{2}{*}{$\begin{array}{c}\text { S. aureus } \\
\text { carriers }\end{array}$} & $\begin{array}{c}\text { All sample } \\
\text { size (n.200) }\end{array}$ & Carriers (no.74) \\
\cline { 2 - 3 } & No. \% & No. \% \\
\hline Nose & $53(26.5)$ & $53(71.6)$ \\
\hline Hand & $8(4.0)$ & $8(10.8)$ \\
\hline Nose and Hand & $13(6.5)$ & $13(17.6)$ \\
\hline Total & $74(37)$ & $74(100.0)$ \\
\hline
\end{tabular}

$P$-Value $<0.001$

\subsection{Prevalence of $S$. aureus carriers and MRSA status}

Table 6 shows that MRSA was detected among 54(73\%) of the $S$. aureus carriers and it represents $27 \%$ of the studied population.

Table 6. Prevalence of S. aureus carriers and MRSA status

\begin{tabular}{|c|c|c|c|}
\hline \multirow{2}{*}{$\begin{array}{c}\text { S. aureus } \\
\text { carriers }\end{array}$} & \multicolumn{2}{|c|}{ MRSA status } & \multirow{2}{*}{ Total No. (\%) } \\
\cline { 2 - 3 } & $\begin{array}{c}\text { Positive } \\
\text { (\%) }\end{array}$ & $\begin{array}{c}\text { Negative } \\
\text { (\%) }\end{array}$ & \\
\hline Yes & $54(73)$ & $20(27)$ & $74(37)$ \\
\hline No & $\begin{array}{c}\text { Not } \\
\text { applicable }\end{array}$ & $126(63)$ & $126(63)$ \\
\hline Total No. (\%) & $54(27)$ & $146(73)$ & $200(100.0)$ \\
\hline
\end{tabular}

3.6 Prevalence of $S$. aureus carriers and vancomycin resistant $S$. aureus status

No cases of Vancomycin Resistant Staphylococcus aureus (VRSA) were detected among all S. aureus food handlers' carriers.

\section{DISCUSSION}

$S$ aureus is involved in nearly all Staphylococcal food poisoning. Food handlers are usually considered as one of the primary sources of these organisms. However, it is difficult to identify the source of the strains implicated in Staphylococcal food poisoning outbreaks. The major source of food contamination via direct contact or through respiratory secretions is food handlers carrying enterotoxinproducing $S$. aureus in their noses or on their hands.
Moreover, food handlers have been accepted to play an important role in the transmission of foodborne diseases; imparting important to the global incidence and burden of diseases (Omololu-Aso et al., 2017).

\subsection{Demographic Characteristics of Food Handlers}

In the present study, all the food handlers were male and this might be due to the reluctance of the female, the tradition and customs of the region that may prevent female from working in the restaurants or public places, and indeed, the owners of public places in Duhok recruit foreigner workers. A similar result was obtained by Simsek et al., (2009) who found that (299) food handlers in Sanliurfa, in South-eastern Anatolia are males because the majority of women in Southern Anatolia are unemployed. Habiballah et al., (2017) found that majority of workers $(81.6 \%)$, who are working in tourist restaurants in Irbid, Jordan were males; they found that females are not eager to work in restaurants (Kasturwar and Shafee 2011). Other studies revealed that their samples are mixed near to equal percentages (Kasturwar and Shafee 2011; El-Shenawy et al., 2014; Castro et al., 2016). Regarding the educational levels, the majority of food handlers $(96.5 \%)$ have high school or less educational levels, because less educated people have little chances to work in high ranking jobs. El-Shenawy et al., (2014) mentioned that all of their study samples are either illiterate or high school educated, while Kasturwar and Shafee, (2011) found that about only $20 \%$ of food handlers having a degree above high school level. In this study, the percentage of cooks $(36.5 \%)$ is slightly more than waiters $(35.5 \%)$ in contrast to a study in Karimnagar, India, were the majority of food handlers were serving food (waiters) $60.2 \%$ and only $12 \%$ working in food preparations (cooks) (Kasturwar and Shafee, 2011). Due to the financial crisis in Kurdistan region that started in 2014, many companies and institutions reduced their manpower including restaurants in Duhok city. They reduced the number of waiters while kept their chefs and even many of the owners and their family members worked as waiters to ease the financial burden on them.

\subsection{Prevalence of $S$. aureus carrier}

The current study revealed that $37 \%$ of food handlers are carriers of $S$. aureus, while Saeed, (2015) found about $29.24 \%(n=106)$ of food handlers in restaurants and cafeterias of Duhok city are carriers of $S$. aureus. Another study was done in Tikrit, Iraq by Alsamarai et al., (2015) who found that $28 \%(\mathrm{n}=100)$ of studied food handlers were carrier for S. aureus. Alhashimi et al., (2017) revealed that the prevalence of nasal carriage of $S$. aureus among 332 food handles in Karbala city, Iraq was $30.1 \%$. A further study was done in Turkey; in which $S$. aureus was lower than that of the current study 20\% (Vatansever et al., 2016). Mainous et al., (2006) estimated that about $32.40 \%$ of the total United States population (86.9 million) was colonized with $S$. aureus. Meanwhile, another study among 200 participants working in three different food processing plants in Egypt that reported the prevalence rate of $S$. aureus $38 \%$ that are in accordance with our results (EL- Shenawy et al., 2014), and the prevalence of $S$. aureus in Makkah city among food handlers working in city kitchens was $40.3 \%$ (Ahmed and Mashat, 2014). In addition to all of the previous studies, higher $S$. aureus carrier rates among food handlers were recorded in many studies such as the study done among 140 food handlers in public hospitals in Salvador city, Brazil, were the carrier rates were $50 \%$ (Ferreira et al., 2014), while higher rate $57.7 \%$ detected in Gaborone, Botswana. $(\mathrm{n}=200)$ (Loeto et al., 2017). The ability of $S$. aureus to colonize or infect its host is related to its ability to express virulence factors that facilitate their adherence to surfaces, cause damage or its ability to evade host's immune system (Udo et al., 2009). 


\subsection{Prevalence of $S$. aureus carriers according to anatomical sites}

Staphylococcus aureus is part of the commensal flora of human skin and mucosal surfaces. The main site for $S$. aureus in human carriers is the nose, which may be colonized during the first few days of life. Strains present in the nasal cavity may contaminate the hands and nasal carriers can thus readily become skin carriers (Hatakka et al., 2000). Approximately $20 \%$ (range, $12 \%$ to $30 \%$ ) of healthy people are persistent $S$. aureus nasal carriers, $30 \%$ (range, $16 \%$ to $70 \%$ ) are intermittent carriers, and 50\% (range, $16 \%$ to $69 \%$ ) are noncarriers (Yan et al., 2015). Persistent carriers usually carry the same strain for extended periods of time, whereas intermittent carriers tend to host different strains over time. The presence of $S$. aureus in the hands of the general population range from $8-28 \%$, according to independent surveys (Hatakka et al., 2000).

The prevalence of $S$. aureus nasal carriage varies by geographical location, age, gender, and ethnicity. The carriage is highest amongst newborns (up to $70 \%$ ) but steadily decreases with age (Aryee and Edgeworth, 2017). Rates of carriage have also been found to be higher in patients with certain diseases like diabetes mellitus, intravenous drug addicts, haemodialysis patients, surgical patients and AIDS patients. Despite the fact that $S$. aureus is found at multiple body sites, most studies have only focused on nasal carriage (Aryee and Edgeworth, 2017). The present study shows that the distribution of carriers according to the anatomical sites of swab collections was from the nasal cavity in $71.6 \%$ of (53 out of 74) of carriers, $10.8 \%$ from the hands (skin) and in $17.6 \%$ the $S$. aureus was isolated from both sites (nasal cavity and hand). (Vatansever et al., 2016) investigated 282 food workers in Kars city, Turkey. They took swabs from the nose, mouth, and hands. S. aureus was isolated from $56(20 \%)$ of food workers which involving $32(57 \%)$ isolates from the nasal nares, $13(23 \%)$ isolates from the mouth and $11(20 \%)$ isolates from the hands of food handlers respectively. In Portugal, the prevalence of $S$. aureus among the studied population was $24.7 \%(\mathrm{n}=162)$, the distribution of carriers according to the sites of swab taking was $32(19.8 \%), 18$ $(11.1 \%)$ and $10(6.2 \%)$ from nose, hands and both sites respectively (Castro et al., 2016).

In contrast, in (Ferreira et al., 2014) study S. aureus detected from the skin in $50 \%$ of carriers and less detected from the nasal cavity 29.3. In another study of the prevalence of $S$. aureus carriage among food workers at the cafeteria of the Federal University of Technology, Nigeria showed the $S$. aureus was isolated from $28(51.85 \%)$ of the 54 food handlers examined, 21 (38.9\%) harbour S. aureus in their nasal cavity, $11(20.4 \%)$ in their throat and $6(11.1 \%)$ in their both sites (Emeakaroha et al., 2017). The distribution of the microorganism varied according to sites on the body, with the nasal cavity harbouring higher numbers of isolates $(44.6 \%)$, while the hand was $(30.9 \%)$ and face was $(24.5 \%)$ (Loeto et al., 2017).

\subsection{Prevalence of MRSA}

In our study, the prevalence of MRSA among the study population was $27 \%$. This result was slightly different from other studies done in Duhok province. (Habeeb et al., 2014) conducted a big study in Duhok province and they found that the MRSA rates had widely different between secondary school students' group (2\%) (10/489) and health care workers $(12 \%)(61 / 510)$. Three separate studies conducted in Zakho city, the researchers found that the MRSA rates were relatively low among University students (4.2\%), and 4\% among primary school students, while higher rates $13.7 \%$ detected among health care workers (Hussein et al., 2010; Assafi et al., 2015). However, (Saeed, 2015) found that
$22.5 \%$ of food handlers serving in restaurants and cafeterias in Duhok city were positive for MRSA. Our results were in line with two other studies (Alsamarai et al., 2015) study who demonstrated the MRSA among $28 \%$ of food handlers in Tikrit, and (Ferreira et al., 2014) study who demonstrated the MRSA among $28.6 \%$ of food handlers. The higher prevalence rate of MRSA was observed in a study done in Sweden among household contacts was $(36.8 \%)(42 / 114)$ (Johansson et al., 2007). Also, a higher MRSA rate detected by (Wolde et al., 2016), they found that $92.5 \%$ of food handlers of Jigjiga university student's cafeteria were MRSA carrier. Lower MRSA rate $9.8 \%$ was reported among food handlers working in Gondar university in Ethiopia (Dagnew et al., 2012). (Shokouhi et al., 2017 ) found that only $1.25 \%$ of the studied population in the tertiary outpatient center in Iran had MRSA. In contrary to our study, no cases of MRSA were detected by other studies (Castro et al., 2016; Vatansever et al., 2016). Many different factors contributed in the distribution of $S$. aureus and MRSA including crowded housing, bad hygienic practices, sharing of personal utensils, recurrent antibiotic usage, hospital admissions and intravenous drug addicts (Braga et al., 2014; Assafi et al., 2017).

\subsection{Prevalence of VRSA}

Vancomycin is considered one of the last options of treatment for $S$. aureus infections that are resistant to other antibiotics. Analysis of different studies showed the emergence of VRSA from different parts of the neighboring countries (Tiwari and Sen, 2006; Askari et al., 2012). Fortunately, no VRSA isolates were found in this study. Similar results obtained in many studies done in Duhok province (Hussein et al., 2010; Habeeb et al., 2014; Saeed, 2015). This might be attributed to many reasons like vancomycin which had been used rarely in Iraq during the United Nation's sanction period from 1990 to 2003; the drug was expensive and was not available in many health facilities. Also, our result was in accordance with the results of neighboring countries (Udo et al., 2009; Dangnew et al., 2012; Shokouhi et al., 2017).

In contrast, Alsamarai et al., (2015) revealed that the $18.6 \%$ of studied food workers in Samara restaurants had vancomycinresistant $S$. aureus and Loeto et al., (2017) found that $27.3 \%$ of food handlers with MRSA also were resistant to vancomycin; this rate is near to that of the study done in Maharashtra among food handlers working in medical college restaurant (26.5\%) (Kasturwar and Shafee, 2011). Moreover, Ferraria et al., (2014) found a high percentage of VRSA $39.2 \%$ from the food handlers' hands and less percentage $23.5 \%$ of VRSA from their anterior nares.

\section{CONCLUSION}

The study revealed a high prevalence of MRSA among food handlers in Duhok city. Food handlers in public places are required to go through regular screening for both nasal and skin carriage of $S$. aureus for the early detection and treatment of carriers so as to protect the community from staphylococcal food poisoning and the spread of resistant $S$. aureus strains among the population.

\section{COMPETING INTERESTS}

The authors declare that they have no competing interests.

\section{RECOMMENDATIONS}

The current study recommends the demand for the regular screening of food handlers in all public places for both nasal and skin carriage of $S$. aureus in order to early detection and effective treatment of carriers so as to protect the community from staphylococcal food poisoning and the spread of resistant $S$. 
aureus strains among the population. As proven, many staphylococcal foods borne disease is mostly caused by incorrect food handling practices. It is recommended to give proper training courses to food handlers so as to prevent the contamination of food.

\section{REFERENCES}

Alhashimi H M, Ahmed M M, Mustafa J M (2017). Nasal carriage of enterotoxigenic Staphylococcus aureus among food handlers in Kerbala city. Karbala International Journal of Modern Science,3: 74.doi.org/10.1016/j.kijoms.2017.02.003.

Ahmed O B and Mashat B H (2014). Prevalence of classical enterotoxin genes in Staphylococcus aureus isolated from food handlers in Makkah city kitchens. Asian Journal of Science and Technology. Umm Al-Qura University, Makkah, Saudi Arabia., 5(11): 727-73.

Aryee A and Edgeworth J D (2017). Carriage, Clinical Microbiology and transmission of Staphylococcus aureus. In: Bagnoli F, Rappuoli R, Grandi G, editors. Staphylococcus aureus: Microbiology, Pathology, Immunology, Therapy and Prophylaxis. Springer International Publishing Switzerland.pp.1-14. DOI 10.1007/82_2016_5.

Askari Z, Sadeghian A, Sadeghian H, Ghazvini K, Safdari H (2012). Antibiotic Resistance Pattern of Hospital Isolates of Staphylococcus aureus in Mashhad-Iran During 2009 - 2011. Archives of Clinical Infectious Diseases, 7(3): 968.DOI: 10.5812 /archcid.14468.

Assafi MS, Mohammed RQ, Hussein NR (2015). Nasal Carriage Rates of Staphylococcus aureus and CA-Methicillin Resistant $S$. aureus among University Students. Journal of Microbiology Research ,5(4): 12327.DOI: 10.5923/j.icrobiology.20150504.01.

Assafi MS, Polse RF, Hussein NR, Haji AH, Issa AR (2017).The prevalence of $S$. aureus nasal colonisation and its antibiotic sensitivity pattern amongst primary school pupils .Science Journal of University of Zakho, 5(1):7-10.

Alsamarai A M, Abbas H M, Attia QM (2015). Nasal carriage of methicillin-resistant Staph aureus in food provider in restaurant at Samara city. International Journal of Pharmacy and Pharmaceutical Sciences, 4 (06): 50-58.

Braga ED, Aguiar-Alves F, de Freitas Mde F, de e Silva MO, Correa TV, Snyder RE et al, (2014). High prevalence of Staphylococcus aureus and methicillin resistant $S$. aureus colonization among Healthy children attending public day care centers in informal settlements in a large urban center in Brazil. BMC Infectious Diseases, 6;14:538. doi: 10. 1186/ 1471-2334-14-538.

Castro A, Santos C, Meireles H, Silva J, Teixeira P (2015). Food handlers as potential sources of dissemination of virulent strains of Staphylococcus aureus in the community. Journal of Infection and Public Health, 9: 153-160.

Clinical and Laboratory Standards Institute (2017). Performance Standards for Antimicrobial Susceptibility Testing. $27^{\text {th }}$ ed. Wayne, Pennsylvania.

Dagnew M, Tiruneh M, Moges F, Tekeste Z (2012). Survey of nasal carriage of Staphylococcus aureus and intestinal parasites among food handlers working at Gondar University, Northwest Ethiopia. BMC public Health, 12(1): 837.doi: 10.1186/1471 -2458-12-837.

Directorate of Preventive Health Affairs (2017). Department of Health Inspection. DPHA, Duhok.

El-Shenawy M, Tawfeek M, El-Hosseiny L, El-Shenawy M, Farag A, Baghdadi H, et al. (2014) Cross Sectional Study of Skin Carriage and Enterotoxigenicity of Staphylococcus aureus among Food Handlers. Open Journal of Medical Microbiology,4(1): Article ID: 43014, 7pages.DOI:10.4236/ojmm.2014.41003.

Emeakaroha, Chioma M, Nkwocha, Gertrude I, Adieze, Chibuzo N et al, (2017). Antimicrobial susceptibility pattern of Staphylococcus aureus, and their nasal and throat carriage among food handlers at the Federal University of Technology, Owerri Nigeria. International Journal of Biomedical Science, 6(3): 1-7.

Ferreira J S, Costa W L, Cerqueira E S, Carvalho J S, Oliveira L C Almeida R C (2014). Food handler-associated methicillin-resistant Staphylococcus aureus in public hospitals in Salvador, Brazil. Food Control, 37: 395-400. doi.org/ 10. $1016 /$ j. foodcont.2013.09.062.

Habeeb A, Hussein NR, Assai MS, Al-Dabbagh SA (2014). Methicillin resistant Staphylococcus aureus nasal colonization among secondary school students at Duhok City-Iraq. Journal of Microbiology and Infectious Diseases, 4(2): 59-63. doi: 10.5799/ ahinjs. 02. 2014. 02.0128.

Habiballah M A, Al-Shakhsheer F, Al-Ababneh M M (2017). Restaurant Employees' Food Handling Practices in Irbid City, Jordan. J Tourism and Hospitality Management ,5(1): 81-89. doi. org/ 10.15640/jthm. v5n1a9.

Hatakka M, Björkroth K J, Asplund K, Mäki-Petäys N, Korkeala H J (2000). Genotypes and enterotoxicity of Staphylococcus aureus isolated from the hands and nasal cavities of flightcatering employees. Journal of food protection, 63(11): 148791.

Hussein N R, Assafi M S, Ijaz T (2010). Methicillin-resistant

Staphylococcus aureus nasal colonisation amongst healthcare workers in Kurdistan Region, Iraq. Journal of Global Antimicrobial Resistance, 9: 78-81. doi.org/ 10. 1016 / j. jgar.2017.01.010.

Johansson PJ, Gustafsson EB, Ringberg H (2007). High prevalence of MRSA in household contacts. Scand Journal of Infectious Diseases, 39(9):764-8.

Kasturwar N B and Shafee M (2011). Knowledge, Practices and Prevalence of MRSA among Food Handlers. International Journal of Biological Medical Research, 2(4): 889 -894.

Loeto D, Matsheka M I, Gashe B A (2017). Enterotoxigenic and antibiotic resistance determination of Staphylococcus aureus strains isolated from food handlers in Gaborone, Botswana. Journal of Food Protection,70(12): 2764-8.

Mainous A G, Hueston WJ, Everett C J, Diaz V A (2006). Nasal Carriage of Staphylococcus aureus and Methicillin-Resistant S. aureus in the United States, 2001-2002. Annals of Family Medicine, 4: 132-7. DOI: 10.1370/afm.526.

Mossong J, Decruyenaere F, Moris G, Ragimbeau C, Olinger C, Johler $\mathrm{S}$ et al (2015). Investigation of a staphylococcal food poisoning outbreak combining case-control, traditional typing and whole genome sequencing methods, Luxembourg, June 2014. Euro Sur veil, 20(45): pp.30059. DOI: Http:// dx.doi.org/10.2807/1560-7917. ES. 2015.20.45.30059

Omololu-Aso J, Omololu-Aso O O, Otusanya O O, Ochada H C, Shesha A (2017). Nasal Colonization of Methicillin Resistance Staphylococcus aureus among Food Handlers in the Eateries Obafemi Awolowo University Ile Ife, Nigeria. Journal of Clinical Nutrition and Dietetics, 3(1:9): 1-4. DOI: 10.4172/2472-1921.100043

Saeed AY (2015). Enterotoxigenicity and antibiogram profile of Staphylococcus aureus isolated from food handlers in restaurants and cafeterias in Duhok city, Iraq. Journal of American science, 11(3s) : 21-24.

Shokouhi S, Darazam I, Zamanian M H (2017). Community-acquired methicillin-resistant Staphylococcus aureus carriage rate and antimicrobial susceptibility in a tertiary center, Iran. Journal of Research in Medical Sciences, 22(1): 71. DOI: 10.4103/ jrms. JRMS 83316.

Simsek Z, Koruk I, Copur A C, Gürses G (2009). Prevalence of Staphylococcus aureus and intestinal parasites among food handlers in Sanliurfa, Southeastern Anatolia. Journal of public health management and Practice, 15(6): 518-23.

Tiwari HK and Sen MR (2006). Emergence of vancomycin resistant Staphylococcus aureus (VRSA) from a tertiary care hospital from northern part of India. BMC Infectious Diseases, 6:156.

Udo E E, Al-Mufti S, Albert M J (2009). The prevalence of antimicrobial resistance and carriage of virulence genes in Staphylococcus aureus isolated from food handlers in Kuwait City restaurants. $B M C$ research notes,2(1): 108. doi: 10. 1186/1756-0500-2-108.

Vandepitte J, Verhaegen K, Engbaek P, Rohner P, Piot C (2003). Basic Laboratory Procedures in Clinical Bacteriology. 2th ed. Geneva: WHO. pp. 111-7.

Vatansever L, Sezer Ç, Bilge N (2016). Carriage rate and methicillin resistance of Staphylococcus aureus in food handlers in Kars City, Turkey . Springer Plus, 5(1): 608. DOI 10.1186/s40064016-2278-2.

Wolde T, Abate M, Mehari L (2016). Prevalence and Antibiotics Resistance Pattern of Staphylococcus aureus among Food Handlers of Jigjiga University Student's Cafeteria. IJSRET, 2(1): 476-8. 
World Health Organization (2015). WHO Estimates of The Global Burden of Foodborne Diseases: Foodborne Disease Burden Epidemiology Reference Group 2007-2015. Geneva: WHO.

Yan X, Song Y, Yu X, Tao X, Yan J, Luo F et al, (2015). Factors associated with Staphylococcus aureus nasal carriage among healthy people in Northern China. Clincal Microbiology Infection, 21: 157 - 162. http://dx.doi.org/10. 1016/j. cmi. 2014.08.023. 